\section{Coupling soil-vegetation- atmosphere-transfer model with energy balance model for estimating energy and water vapor fluxes over an olive grove in a semi-arid region}

\author{
Jamal Ezzahar,,2 Salah Er-Raki, ${ }^{3}$ \\ Hamid Marah,' Said Khabba, ${ }^{2}$ Noureddine \\ Amenzou, ${ }^{1}$ Ghani Chehbouni ${ }^{4}$ \\ ${ }^{1}$ Water and Climate Unity, CNESTEN, \\ Rabat, Morocco; '2Department of Physics, \\ Faculty of Sciences Semlalia, Marrakech, \\ Morocco; ${ }^{3} \mathrm{LP2M} 2 \mathrm{E}$, Équipe \\ d'Instrumentation, Métrologie et \\ Procédés (IMP), Department of Physics, \\ Faculty of Sciences and Technology, \\ Marrakech, Morocco; ${ }^{4}$ CESBIO - UMR \\ CNRS-CNES-IRD-UPS, Toulouse, France
}

\section{Abstract}

Simple soil-vegetation-transfer (SVAT) and energy balance models were used to estimate the surface turbulent fluxes (i.e. sensible and latent heat fluxes) over a complex olive grove using thermal infra-red surface temperature (TIRST). This approach used a dual source SVAT model to calculate the sensible heat fluxes from radiometric surface temperature. These fluxes were then used together with the estimates of the available energy also derived from TIRST to estimate the latent heat flux by applying the first law of thermodynamics i.e. the conservation of energy principle. The data used to validate this approach were collected over an irrigated olive grove site located in central Morocco near Marrakech. Mass and energy fluxes, as well as micrometeorological parameters, were continuously measured during the year 2003. The comparison between estimated and measured daily sensible heat fluxes yielded an acceptable agreement in spite of the complexity of the study surface with a correlation coefficient $\left(\mathrm{R}^{2}=0.86\right)$ and root mean square error (RMSE) of $28 \mathrm{Wm}^{-2}$. For the latent heat fluxes, the statistical result for the comparison between estimated and measured daily values showed a larger scatter than that revealed for the sensible heat fluxes $\left(\mathrm{R}^{2}=0.75\right.$; RMSE $\left.=31.42 \mathrm{Wm}^{-2}\right)$. However, the correspondence is to be considered acceptable given the difficulty in estimating latent heat flux over such a complex field. Therefore, it can be concluded that, in spite of the simplicity of the proposed approach, it can be considered a suitable tool for estimating the turbulent fluxes using TIRST over complex surfaces.

\section{Introduction}

An accurate determination of regional turbulent fluxes of sensible heat $(\mathrm{H})$ and latent heat (LE) at the land-atmosphere interface are required in a wide variety of applications. Agricultural and forestry research uses these convective fluxes to predict crop growth. Meteorologists need accurate estimates of latent and sensible heat surface fluxes for weather predictions. Biologists aim to have a better understanding of how ecosystems function. Climatologists need estimates of how the land surface and its vegetation may influence climate, and hydrologists use estimates for water balance simulations on different scales.

With the high cost of measuring turbulent fluxes, a strong emphasis has been directed toward understanding the processes governing the exchange of water and energy between the land surface and the atmosphere in order to model turbulent fluxes at the different ranges of the space-time scale. The model parameterization of the interaction between a land surface and the atmosphere is known as a soilvegetation-atmosphere transfer scheme (SVAT). Numerous SVAT schemes of varying complexity have been developed in recent years. These SVAT schemes have been used in conjunction with thermal infra-red data (i.e. radiometric surface temperature) to estimate accurate turbulent fluxes. ${ }^{1-7}$ Most of these investigations consist of estimating sensible heat flux, net radiation and soil heat flux from thermal infra-red data and calculating latent heat flux as a residual term of the energy balance equation by applying the simplified expression of the first law of thermodynamics. The latter is referred to as the conservation of energy principle, meaning that energy can neither be created nor destroyed, but rather transformed into various forms.

Estimating reliable values of sensible heat flux represents the most problematic aspect of this approach. In such model parameterizations, the soil-vegetation system is treated as a single source of heat exchange with the overlying atmosphere. These kinds of SVAT are classified as one-layer models. The heat flux is related to the difference between the radiometric temperature and the air temperature at a reference height. This approximation is still acceptable over homogenous surfaces where the vegetation is very dense and short or over bare soil. However, in most cases, the landscape is under partial vegetation canopy so that both soil and vegetation components contribute to the sensitive heat exchange. ${ }^{8}$ Therefore, extension of the one-layer models to sparsely vegetated surfaces can produce significant errors in predicted heat fluxes. ${ }^{9}$ In this context, much effort has been made to investigate the parameterization of heat transfer and
Correspondence: Jamal Ezzahar, Water and Climate Unity, CNESTEN, Rabat, Morocco.

E-mail: ezzahar@cnesten.org.ma

Acknowledgments: this research was conducted within the framework of the SUDMED project, the EU funded IRRIMED (www.irrimed.org), and RAF 5058 projects. We are grateful to the International Joint Laboratory (TREMA) for its financial and technical support.

Contributions: all authors agree to the contents and submission of the paper.

Key words: sensible heat flux, latent heat flux soil-vegetation-transfer model, thermal infra-red data, available energy, olive grove, semi-arid region.

Received for publication: 15 June 2011.

Revision received: 23 March 2012.

Accepted for publication: 28 March 2012

This work is licensed under a Creative Commons Attribution 3.0 License (by-nc 3.0).

(C) Copyright J. Ezzahar et al., 2012

Licensee PAGEPress, Italy

Global Meteorology 2012; 1:e1

doi:10.4081/gm.2012.e1

to improve the accuracy in estimating heat fluxes over different land surface cover by developing models which explicitly treat the energy exchanges between the soil, vegetation and the overlying atmosphere. ${ }^{9}$ Lhomme et al. have considered that the soil-vegetation system can be approximated with a two-layer model where the energy fluxes are partitioned between the soil and vegetation. They found that the estimated heat fluxes from thermal infra-red data over the millet crop using a twolayer model showed good results compared to the use of a one-layer model which over-estimates the sensible heat flux.

In this specific study, we will investigate the applicability of the two-layer model developed by Lhomme et al. ${ }^{9}$ over a more complicated surface. The complexities are related to the sparseness of the vegetation, the heterogeneity of the soil characteristics and, most importantly, the heterogeneity in terms of soil moisture induced by the irrigation method of flood irrigation, which has an irregular pattern in space and time. Additionally, the validation of the model will be performed over an extended period (measurements taken over approximately one year) in order to test its consistency for accurately estimating heat fluxes under all weather conditions. Data used in these investigations were collected within the framework of the SUDMED project, ${ }^{10}$ which was carried out in southern Mediterranean regions (Marrakech, Morocco) to assess the spatio-temporal variabil- 
ity of water needs and consumption for irrigated crops under water shortages.

\section{Materials and Methods}

\section{Estimate of turbulent heat fluxes, heat and latent heat}

Conservation of energy (first law of thermodynamics) is such that we can formulate a budget equation for the energy flux at the earth's surface to see where the incoming energy flux is going. The net radiation ( $\mathrm{Rn})$, which is the net effect of incoming and outgoing long and short wave radiation, can: i) vaporize water (latent heat flux, LE); ii) heat the soil [soil heat flux, G (Wm-2)]; iii) heat the atmosphere (sensible heat flux, $\mathrm{H}\left(\mathrm{Wm}^{-2}\right)$; and iv) be absorbed by the crop (strength $\Delta S$ $\left(\mathrm{Wm}^{-2}\right)$. The latter is generally neglected in situations where vegetation is sparse, as is the case of our study site. The energy balance must, therefore, be expressed in its most general form as:

$$
\mathrm{Rn}=\mathrm{LE}+\mathrm{H}+\mathrm{G}
$$

Let us describe the theory which underlies essential aspects of the use of the SVAT model in conjunction with an energy balance model to formulate turbulent heat fluxes: i) the theory of the two-source model (SVAT) proposed for estimating the sensible heat fluxes using thermal infra-red surface temperature (TIRST); ii) a simple model proposed to estimate the available energy (defined as Rn-G) also using TIRST; iii) the latent heat flux is estimated as a residual term of the energy balance equation (Eq. 1).

\section{Soil-vegetation-atmosphere trans- fer model: formulation of sensible heat flux convection}

From a physical point of view, the total sensible heat flux, $H\left(\mathrm{Wm}^{-2}\right)$ in sparse vegetation (Figure 1) can be formulated as:

$$
H=\rho c_{p} \frac{\left(T_{0}-T_{a}\right)}{r_{a}}
$$

where $\rho$ is the air density $\left(\mathrm{kgm}^{-3}\right), \mathrm{cp}$ is the specific heat of air at constant pressure $\left(\mathrm{Jkg}^{-1} \mathrm{~K}^{-1}\right)$, and Ta is the potential air temperature at reference height $(\mathrm{K}), T_{0}$ is the aerodynamic surface temperature $(\mathrm{K})$ and $r_{a}$ is the aerodynamic resistance to heat transfer between the level of apparent sink of momentum and the reference height $\left(\mathrm{sm}^{-1}\right)$. This resistance is calculated by means of the classical formulae, which take into account the stability correction functions for wind and temperature $^{11}$ as:

$$
r_{a}=\frac{1}{k u .}\left[\ln \left(\frac{z_{r}-d}{z_{0}}\right)-\psi_{h}(\zeta)\right]
$$

with

$$
u_{*}=\frac{k u_{a}}{\ln \left(\left(z_{r}-d\right) / z_{0}\right)-\psi_{m}(\xi)}
$$

where $u_{*}$ is the friction velocity, ua is wind speed at reference height, $\mathrm{k}$ is von Karman's constant, $\mathrm{z}_{0}$ is roughness length for momentum, $\psi_{h}$ and $\psi_{m}$ are the stability functions, respectively, for heat and momentum given by Paulson $^{12} \zeta$ is a dimensionless parameter defined as a function of Monin-Obukhov length $\mathrm{L}$, zero displacement height $\mathrm{d}$, and reference height $\mathrm{z}_{\mathrm{r}}$ : as $\zeta=\left(z_{r}-d\right) / L$. $\mathrm{L}$ is defined by:

$$
L=-\frac{u^{3} \cdot \rho c_{p} T_{a}}{k g H}
$$

where $\mathrm{g}$ is the acceleration of gravity.

$\mathrm{T}_{0}$ can be obtained by extrapolating the profile of potential temperature through the roughness sub-layer down to the level where the extrapolated air temperature equals the actual surface temperature. In practice, however, it is very difficult to determine. In order to overcome this problem, we can express the total sensible heat flux as the sum of the contributions emanating from each layer, i.e. from the canopy $\left(\mathrm{H}_{\mathrm{c}}\right)$ and from the soil surface $\left(\mathrm{H}_{\mathrm{s}}\right)$ $\left(\mathrm{H}=\mathrm{H}_{\mathrm{s}}+\mathrm{H}_{\mathrm{c}}\right)$. These two fluxes are, respectively, written as:

$$
H_{c}=\rho c_{p}\left(T_{c}-T_{0}\right) / r_{a c} \quad \text { (6) } \quad \alpha_{w}=2.6 L A I^{0.36}
$$

where $\mathrm{T}_{\mathrm{c}}$ is the canopy temperature, $\mathrm{T}_{\mathrm{s}}$ is the soil temperature, $r_{a s}$ is the aerodynamic resistance between the soil and the canopy source height $\left(\mathrm{s} \mathrm{m}^{-1}\right)$ and $r_{a c}$ is the bulk boundary layer resistance of the canopy $\left(\mathrm{s} \mathrm{m}^{-1}\right)$. Following Shuttleworth and Gurney, ${ }^{13} r_{a s}$ is given by:

$$
\begin{aligned}
& r_{a s}=\frac{h \exp \left(\alpha_{w}\right)}{\alpha_{w} K(h)}\left[\exp \left(\frac{-\alpha_{w} z_{0 s}}{h}\right)\right. \\
& \left.-\exp \left(\frac{-\alpha_{w}\left(d+z_{0 m}\right)}{h}\right)\right]
\end{aligned}
$$

Here, $K(h)$ is the eddy diffusivity at canopy height $\mathrm{h}, z_{0 s}$ is the understory roughness length, assumed to be $0.01 \mathrm{~m} . K(h)$ is written as:

$$
K(h)=\kappa u_{*}(h-d)
$$

where $\kappa$ is the von Karman constant $(=0.4)$, and $u_{*}$ is given by Eq. 4 .

It should be noted that the parameter $\alpha_{w}$, the decay of the eddy diffusivity within the canopy, is often assumed to be constant, with a value of 2.5 , which in fact is the value found for crops with a Leaf Area Index (LAI) of approximately 1 . In the experimental area, average LAI is approximately 3 . Therefore, we have used the formulation found by Lafleur and Rouse ${ }^{14}$ who have expressed $\alpha_{w}$ as a function of LAI:
Reference height

$\mathrm{T}_{\mathrm{a}}$

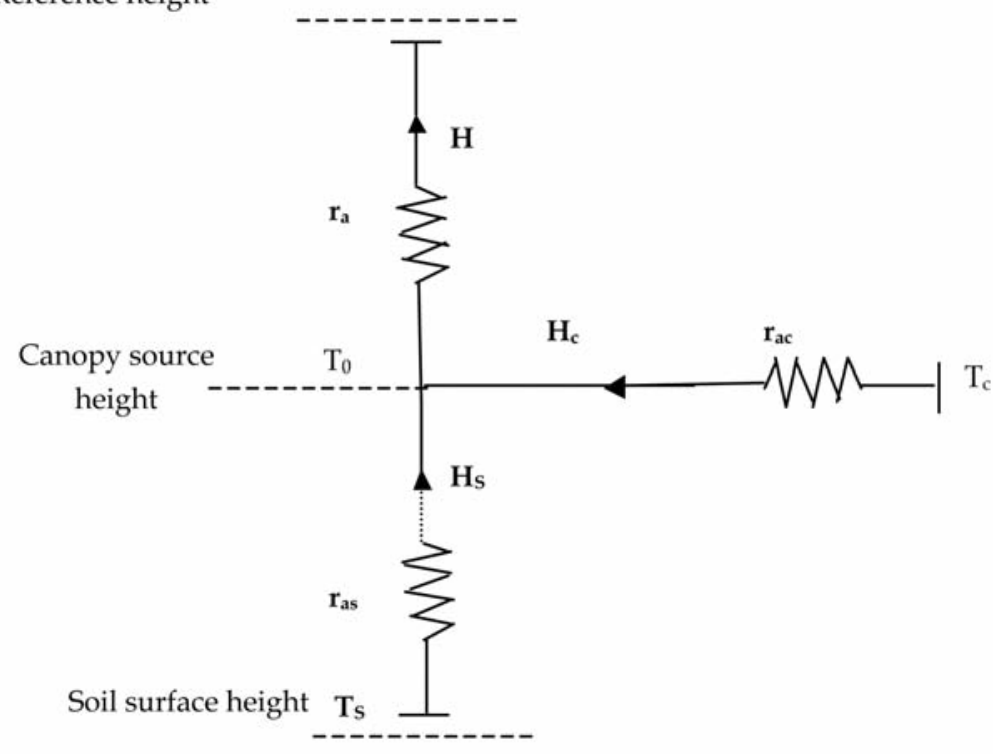

Figure 1. Fluxes and potential-resistance network for a two-layer model of heat transfer. $T_{a}$ is air temperature at a reference height, $T_{c}$ is foliage temperature, $T_{s}$ is soil temperature, and $T_{o}$ is air temperature at canopy source height. 
For the bulk boundary layer resistance of the canopy $\left(r_{a c}\right)$, Choudhury and Monteith ${ }^{15}$ obtained this parameter by integrating the leaf boundary layer conductance, which is the reciprocal of the boundary layer resistance and a function of wind speed within the canopy, over the canopy height. Note that the LAI is assumed to be distributed uniformly over the canopy height

$$
r_{a c}=\frac{\alpha_{w} \sqrt{\frac{w}{u(h)}}}{4 \alpha_{0} L A I\left[1-\exp \left(-\frac{\alpha_{w}}{2}\right)\right]}
$$

where $u(h)$ is wind velocity at the top of the canopy $\left(\mathrm{m} \mathrm{s}^{-1}\right), \mathrm{w}$ is the leaf width $(=0.015 \mathrm{~m})$ and $\alpha_{0}$ is a constant $\left(=0.005 \mathrm{~m} \mathrm{~s}^{-1 / 2}\right)$.

Summing Eqs. (6) and (7) gives for the total sensible heat flux:

$$
H_{c}=\rho c_{p}\left(T_{c}-T_{0}\right) / r_{e}
$$

where $T_{e}$ is the equivalent temperature $(\mathrm{K})$, the weighted mean of the soil $\left(T_{s}\right)$ and canopy $\left(T_{c}\right)$ temperature, defined by:

$$
T_{e}=\frac{\left(r_{a c} T_{s}+r_{a s} T_{c}\right)}{\left(r_{a s}+r_{a c}\right)}
$$

and $r_{e}$ is the equivalent resistance $\left(\mathrm{s} \mathrm{m}^{-1}\right)$, given by:

$$
r_{e}=\frac{r_{a c} r_{a s}}{\left(r_{a c}+r_{a s}\right)}
$$

Lhomme et al. ${ }^{9}$ have demonstrated that combining Eqs. (2) and (12) leads to

$$
H=\rho c_{p} \frac{\left(T_{e}-T_{a}\right)}{\left(r_{a}+r_{e}\right)}
$$

However, Eq. (15) requires an accurate knowledge of $T_{s}$ and $T_{c}$, which is not easily obtainable from remote sensing systems. Lhomme et al. ${ }^{9}$ have shown that $\mathrm{T}_{\mathrm{e}}$ can be related to $T_{r}$, the radiative surface temperature (K) by:

$$
T_{c}=T_{r}=-c\left(T_{s}-T_{c}\right)=-c \delta T
$$

with c defined by:

$$
c=\left[\frac{1}{1+\left(r_{a c} / r_{a s}\right)}\right]-f
$$

and $\int$ is the fractional vegetation cover (for the experimental site $\delta=0.6$ ). Lhomme et al. ${ }^{9}$ have shown that $\delta T$ can be approximated by:

$$
\delta T=\alpha\left(T_{r}-T_{a}\right)^{m}
$$

with $\alpha$ and $m$ as empirical coefficients (a positive real number and $\mathrm{m}$ positive integer) which can be determined statistically by adjusting $\mathrm{H}$ estimated to $\mathrm{H}$ observed. Now, we can rewrite Eq. (15) into an expression for the estimation of sensible heat flux as a function of the difference between radiative surface temperature and air temperature:

$$
H=\rho c_{p}\left[\frac{\left(T_{r}-T_{a}\right)-c \delta T}{r_{a}+r_{e}}\right]
$$

\section{Available energy}

\section{Net radiation}

Net radiation $\left(R_{n}\right)$, which corresponds to the surface radiative balance in the solar domain (0.15-4 mm) and the thermal domain (3-100 $\mathrm{mm}$ ), is the source of energy for biophysical processes at the surface and greatly impacts climatic processes at all scales. It is the most fundamental variable for surface energy balance studies. In the current study, $R_{n}$ is evaluated as follows:

$$
R_{n}=(1-\alpha) R_{g}+\varepsilon_{s} R_{a}-R_{t}
$$

where $\alpha$ is the surface albedo, $R_{g}$ is the solar global radiation $\left[\mathrm{W} \mathrm{m} \mathrm{m}^{-2}\right], \varepsilon_{s}$ is the surface emissivity (in practical work a value of 0.98 may be taken for crop canopies, ${ }^{16,17} \mathrm{R}_{\mathrm{a}}$ is the atmospheric radiation which is emitted by air molecules $\left[\mathrm{W} \mathrm{m}^{-2}\right.$ ], and $\mathrm{R}_{\mathrm{t}}$ is the terrestrial radiation which is emitted by the surface [W $\mathrm{m}^{-2}$ ]. By using the Stefan-Boltzman equation, ${ }^{18} R_{a}$ and $R_{t}$ can be expressed as a function of air and surface temperatures, respectively. Then, Eq. (20) can be rewritten as:

$$
R_{n}=(1-\alpha) R_{g}+\varepsilon_{s} \sigma\left(\varepsilon_{a} T_{a}^{4}-T_{r}^{4}\right)
$$

with $\sigma$ as the Stefan-Boltzman constant $\left(5.67 \times 10^{-8} \mathrm{Wm}^{-2} \mathrm{~K}^{-4}\right)$ and $\varepsilon_{a}$ as the emissivity of the atmosphere. The latter is estimated using the expression proposed by Brutsaert et al..$^{19}$ as:

$$
\delta_{a}=1.24\left(e_{a} / T_{a}\right)^{1 / 7}
$$

with $e_{a}$ as the air vapour pressure (hPa).

\section{Soil heat flux}

Soil heat flux (G) is an important component of the surface energy balance, especially over sparse vegetation. However, due to the complexity of surface cover and physical processes occurring in the soil, the soil heat flux (G) is the most difficult scalar to measure accurately at the appropriate space-scale. Therefore, in several micrometeorological studies, $\mathrm{G}$ is parameterized as a constant proportion of $R_{n}$ (i.e., $G=c R_{n}$ ) that is fixed for the entire day or period of interest.,20-23 In this study, the ratio of the soil heat flux to net radiation was estimated according to Santanello et $a l .{ }^{24}$ as follows:

$$
G / R_{n}=A \cos [2 \pi(t+10800) / B]
$$

where $t$ is the time of day in seconds, and A and $\mathrm{B}$ are adjusting factors which were set by Santanello et al. ${ }^{24}$ of 0.31 and $74,000 \mathrm{~s}$, respectively.

\section{Latent heat flux}

Provided that sensible heat flux $\mathrm{H}$, net radiation $R_{n}$, and soil heat flux $G$ estimates are obtained using the aforementioned formulations, estimated latent heat flux LE can be obtained as the residual term of the energy balance equation by applying the first law of thermodynamics:

$$
\mathrm{LE}=\mathrm{R}_{\mathrm{n}}-\mathrm{G}-\mathrm{H}
$$

\section{Site description and experimental setup}

\section{Site description}

Research work was conducted during the year 2003 (1 January to 31 December) at the 275 ha Agdal irrigated olive grove which is located to the southeast of the city of Marrakech, Morocco ( $\left.31^{\circ} 36^{\prime} \mathrm{N}, 007^{\circ} 58^{\prime} \mathrm{W}\right)$. Figure 2 shows the area of interest on a very high spatial resolution image acquired by the Quickbird satellite ( 0.62 and $2.4 \mathrm{~m}$ in panchromatic and multi-spectral, respectively). This area was characterized by a semiarid Mediterranean climate, with low and irregular rainfall (annual average approx. $240 \mathrm{~mm}$ ), whereas the evaporative demand is around $1.600 \mathrm{~mm}$ per year. The atmosphere is very dry with an average humidity of $56 \%$. The average height of the olive trees is $6 \mathrm{~m}$ with a mean fraction cover of approximately $55 \%$, as obtained from hemispherical canopy photographs (using a Nikon Coolpix 950® with a FC-E8 fish-eye lens converter; field of view $183^{\circ}$ ). Two water basins are used for irrigation. Water is manually diverted to every tree through a ditch network. Each tree is surrounded by a small earthen levy, which retains irrigation water, thus supplying water to every tree. Irrigation is started from the southern border of the field and, depending on available manpower, progresses towards the northern border of the site over approximately 12 days.

\section{Micrometeorological measurements}

The field was equipped with a set of stan- 
dard meteorological instruments to measure wind speed and direction (with a Young Wp200 anemometer), air temperature and humidity (with a Vaisala HMP45AC probe) at $9 \mathrm{~m}$ above the ground. Radiative soil and vegetation temperatures were measured using 2 Precision Infrared Thermocouple Sensors (Apogee). Measurements were sampled at $1 \mathrm{~Hz}$, averaged, and then stored at 30 -min intervals on CR10X dataloggers.

\section{Surface flux measurements}

\section{Available energy}

Net radiation was measured using a CNR1 radiometer which measures separately incoming and outgoing solar and far infrared radiation. The CNR1 was located in a place (at 8.5 $\mathrm{m}$ ) that is representative of the vegetation and soil. The soil heat flux density was measured using heat flux plates (HFT3-L, Campbell Scientific Ltd.) at three locations with contrasting amounts of radiation reaching the soil. The measurement depth was $1 \mathrm{~cm}$. The plates were placed: one below the tree near the trunk in order not to be exposed to direct solar radiation; one exposed directly to solar radiation, and one was placed in an intermediate position. An average of these 3 measurements was made to obtain a representative value. Measurements of net radiation and soil heat flux were sampled at $1 \mathrm{~Hz}$, averaged, and then stored at 30 -min intervals on CR10X dataloggers.

Turbulent flux measurements: sensible and latent heat fluxes

An eddy-covariance systems (EC) was installed to provide continuous measurements of vertical fluxes of heat, water vapor and $\mathrm{CO}$ on the $9.2 \mathrm{~m}$ tall instrument tower. The EC systems consisted of a 3D sonic anemometer (CSAT3, Campbell Scientific Ltd.) which measured the fluctuations in the wind velocity components and temperature, and a Krypton hygrometer (KH20, Campbell Scientific Ltd.) that measured the concentration of water vapour. Raw data were sampled at a rate of 20 $\mathrm{Hz}$ and were recorded using CR5000 datalogger (Campbell Scientific Ltd.), equipped with a $1 \mathrm{~Gb}$ PCMCIA-card for the storage of large raw data files. The half-hourly values of fluxes were later calculated off-line after performing planar fit corrections, ${ }^{25}$ correcting the sonic temperature for the presence of humidity, ${ }^{26}$ frequency response corrections for slow apparatus and path length integration, ${ }^{27}$ the inclusion of the mean vertical velocity according to Van Dijk et al. ${ }^{28}$ and oxygen correction for the Krypton hygrometer, which is sensitive to $\mathrm{O}_{2}{ }^{29}$ For the data processing, we used the eddy covariance processing EC-pack software, developed by the Meteorology and Air Quality Air Quality Group, Wageningen University.
This software is available for download at http://www.met.wau.nl/. Knowledge of the uncertainty is essential for the statistical evaluation of modeled and measured fluxes. This issue has been an active area of micrometeorological research. ${ }^{30-37}$ In order to obtain some idea as to the uncertainly inherent in flux measurements, the error bars in Figure 3 present sensible and latent fluxes. The average flux uncertainties for all used values were approximately $10-12 \%$ for sensible and latent heat fluxes, respectively.

\section{Results and Discussion}

In this study, the Eddy-Covariance (EC) data were used to assess the accuracy of the modeled turbulent fluxes. Therefore, we first analyzed the energy balance flux components.
Indeed, closure of the surface energy balance provides an objective criterion for evaluating EC flux measurements. By ignoring the term of canopy heat storage at a daily time scale, ${ }^{38,39}$ and assuming the principle of conservation of energy, the energy balance closure is defined as $R_{n}-H_{e c}-L_{e c}-G=$ and should be close to zero. $\mathrm{Rn}$ is the measured net radiation, $\mathrm{G}$ is the measured soil heat flux, and $\mathrm{H}$ and LE are the sensible and latent heat fluxes measured from the EC system. Figure 4 shows the plot of $R_{n}-G$ against the sum of the turbulent fluxes $\left(\mathrm{H}_{\mathrm{ec}}+\mathrm{L}_{\mathrm{Eec}}\right)$ for a daily time scale. The linear regression (forced through the origin) yields $\left(\mathrm{Wm}^{-2}\right) \mathrm{R}_{\mathrm{n}}-G=0.97\left(H_{E C}+L E_{E C}\right), R^{2}=0.9$ and the Root Mean Square Error RMSE $=31 \mathrm{Wm}^{-2}$.

In comparison to reports from other experimental studies (the average error in closure ranges from 10-30\% according to Baldocchi et $\left.a l .{ }^{40}\right)$ the energy balance closure obtained here can be considered to be fairly acceptable,

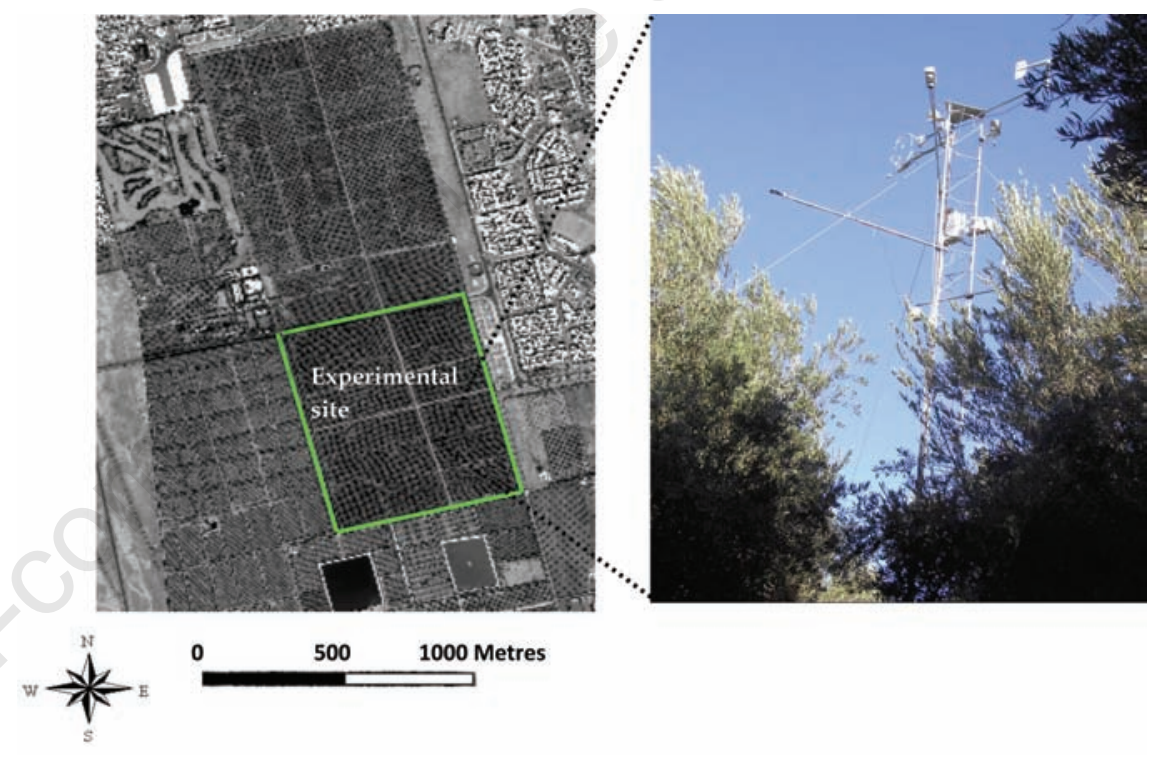

Figure 2. Overview of the study site.
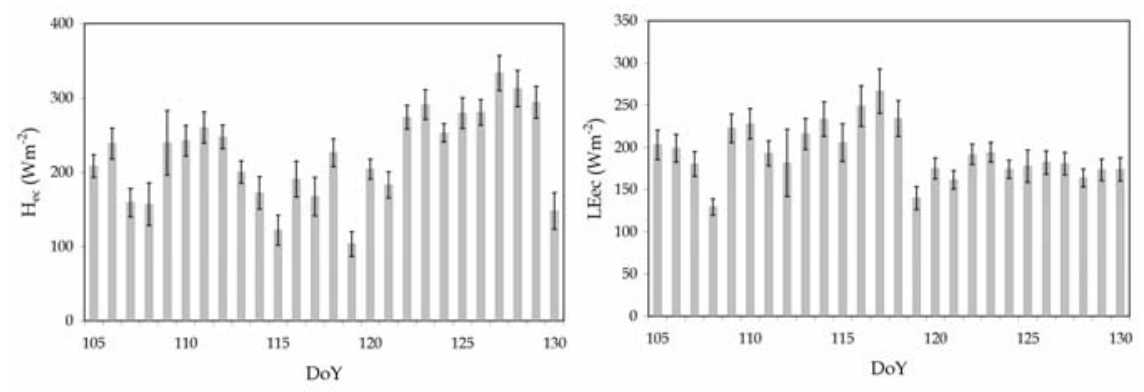

Figure 3. The uncertainty of the sensible and latent heat fluxes. Uncertainty of $\mathbf{H}$ (left panel) and uncertainly of LE (right panel). 
especially if one considers the complexities of the study site (tall and sparse vegetation, and the irrigation method which has an irregular pattern over space and time). Therefore, the EC flux measurements can potentially be used to validate the modeled turbulent fluxes.

In Figure 5, the sensible heat flux measured with the EC system, $\mathrm{H}_{\mathrm{ec}}$, is compared to that simulated from the SVAT model, $\mathrm{H}_{\text {mod }}$, using the measured radiometric surface temperature. This comparison is made on a daily time scale. The linear regression (forced through the origin) yields [ $\left.\mathrm{W} \mathrm{m}^{-2}\right]: H_{\text {mod }} 00.98 H_{e c}, \mathrm{R}^{2}=$ 0.86, and the Root Mean Square Error (RMSE) was approximately $28 \mathrm{Wm}^{-2}$. It should be noted that the comparison included all weather conditions (dry and wet conditions). An attempt was made to study the sensitivity of a set of parameters (i.e. cover fraction, vegetation height and leaf area index) on the modeled sensible heat flux (Table 1). The test was carried out between days 121 and 150 using halfhourly values. The statistical results showed that the model is very sensitive to the cover fraction and the vegetation height.

To illustrate the effect of the irrigation method, a comparison was made during homogeneous conditions (dry conditions and days following rain events) and heterogeneous conditions (during irrigation). The statistical results are presented in Table 2 . It can be seen that there is a very good correlation under homogeneous conditions compared to that obtained during heterogeneous conditions. This was expected given that the SVAT models are based on point measurements with a footprint less than that of the EC system and thus only give reliable results at the homogenous surface. However, taking into account the complexity of the field, the result obtained is very encouraging. Indeed, the nature of the olive grove (relatively tall and sparse, irrigated trees in a semiarid environment) means transfer processes of heat and mass are more complicated than over short crops. Therefore, it can be concluded that, in spite of its simplicity, the SVAT model can be considered suitable for estimating the sensible (convection) heat fluxes using the radiometric surface temperature in difficult environments.

Before evaluating the accuracy of the model to predict the latent heat flux, we first compared initial estimated available energy (denoted $\mathrm{AE}_{\text {est }}$ ) against the ground based measurement (denoted $\mathrm{AE}_{\text {mes }}$ ) on the daily time scale in order to quantify the error associated to the estimated available energy in the calculation of the latent heat flux (Figure 6). The available energy is defined as the difference between the net radiation and the soil heat flux $\left(R_{n}-G\right)$. $A E_{\text {est }}$ was obtained from Eqs. (21) and (23). Taking into account the complexity of the field, the correspondence
Table 1. Statistical results of the sensitivity of a set of parameters [i.e. cover fraction ( $f c$ ), vegetation height (h) and Leaf Area Index (LAI)] on the modeled sensible heat flux.

\begin{tabular}{lcccccccccc}
\hline fc & 0,1 & 0,2 & 0,3 & 0,4 & 0,5 & 0,6 & 0,7 & 0,8 & 0,9 & 1 \\
RMSE & 126.84 & 109.69 & 91,69 & 74.79 & 59.65 & 48.62 & 50.46 & 52.3 & 66.45 & 0.87 \\
$\mathrm{R}^{2}$ & 0.859 & 0.86 & 0.86 & 0.87 & 0.87 & 0.87 & 0.87 & 0.87 & 0.87 & 0.87 \\
$\mathrm{~h}(\mathrm{~m})$ & 3 & 4 & 5 & 6 & 7 & 8 & 9 & 10 & & \\
$\mathrm{RMSE}$ & 85 & 96.4 & 81.8 & 57.63 & 45.5 & 66.9 & 113.4 & 186 & & \\
$\mathrm{R}^{2}$ & 0.85 & 0.85 & 0.86 & 0.87 & 0.87 & 0.877 & 0.87 & 0.86 & & \\
LAI & 1 & 1.5 & 2 & 2,5 & 3 & 3.5 & 4 & & & \\
RMSE & 47 & 47.12 & 46.56 & 45.83 & 45.42 & 45.5 & 46.13 & & & \\
$\mathrm{R}^{2}$ & 0.86 & 0.868 & 0.8714 & 0.87 & 0.875 & 0.87 & 0.88 & & & \\
\hline
\end{tabular}

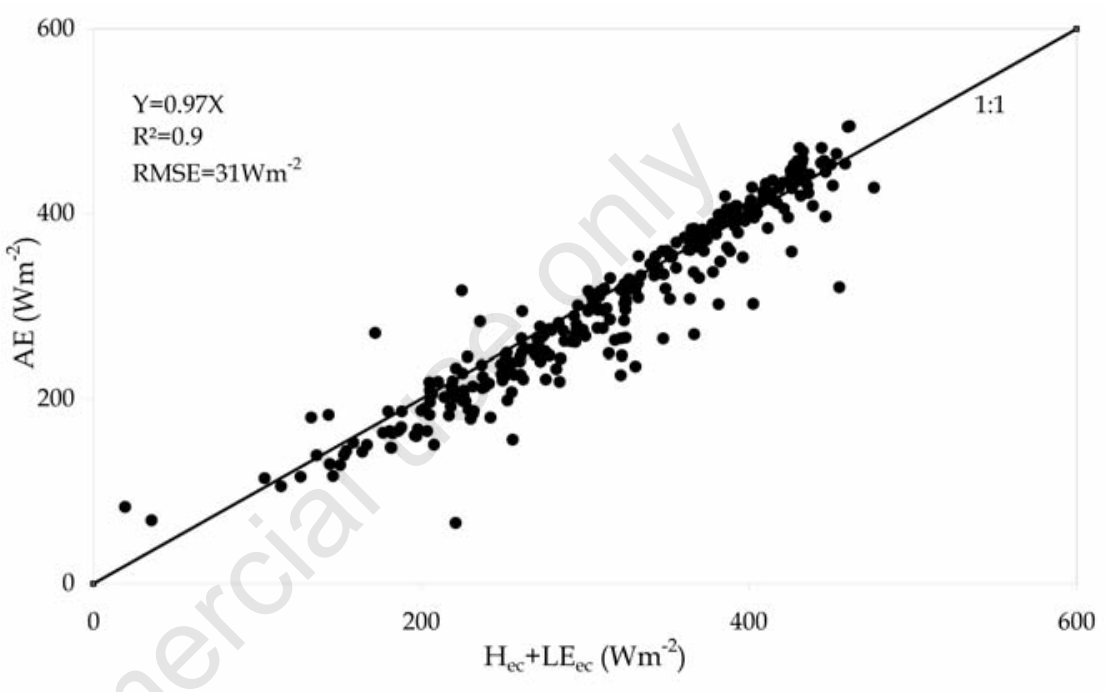

Figure 4. Comparison between daily available energy $\left(A E=R_{n}-G\right)$ and the sum of sensible $\left(\mathrm{H}_{\mathrm{ec}}\right)$ and latent heat $\left(\mathrm{LE}_{\mathrm{ec}}\right)$ fluxes measured by the Eddy-Covariance system.

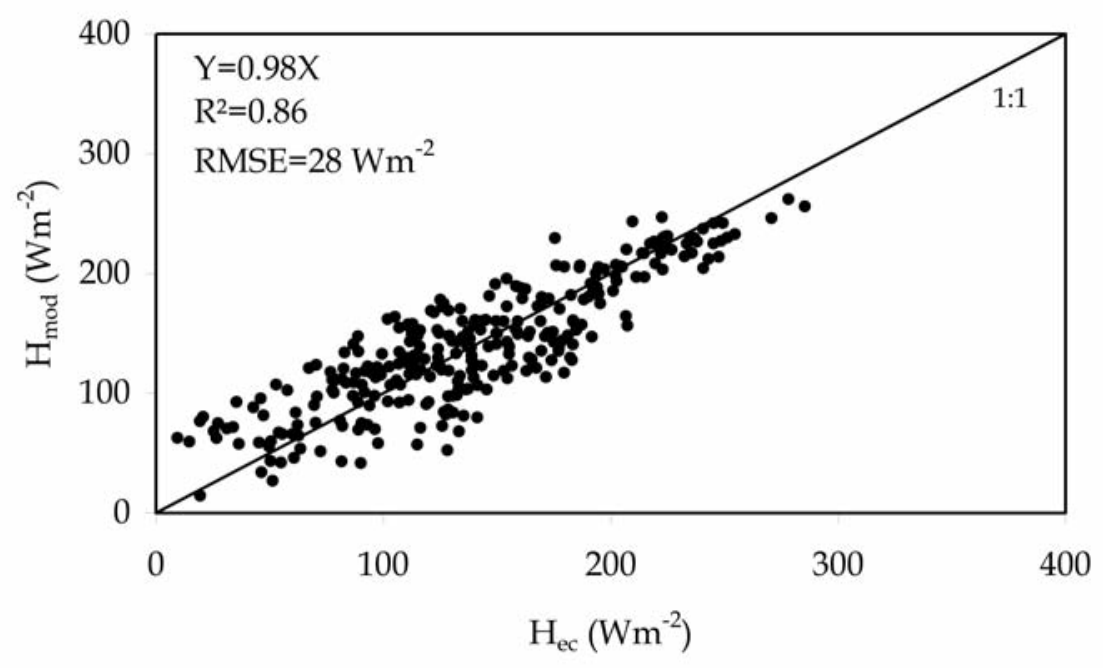

Figure 5. Comparison between daily modeled $\left(\mathrm{H}_{\text {mod }}\right)$ and measured $\left(\mathrm{H}_{\mathrm{ec}}\right)$ sensible heat flux. 
between AEest and $\mathrm{AE}_{\text {mes }}$ was quite good in spite of the remarkable discrepancy. The RMSE value was approximately $31.6 \mathrm{Wm}^{-2}$, and the linear regression forced to the origin yielded a 0.99 slope value and a 0.89 correlation coefficient. A part of the revealed discrepancy can be related to the calculation of the atmospheric emissivity using Brutsaert's formula (Eq. 21) which was only established for clear days. ${ }^{19}$ To illustrate the effect of this assumption, another comparison was made during cloudy and clear sky conditions (Table 2). By analyzing the correlation obtained, it can be concluded that conditions of cloud can create some discrepancies.

By comparing our finding with those obtained by Ezzahar et al. ${ }^{41}$ using the model by $\mathrm{Su}^{23}$ for deriving the soil heat flux, one can be concluded that the use of soil heat flux estimated from the model by Santanello et al. ${ }^{24}$ significantly improves the available energy estimates. Indeed, Ezzahar et $a .^{41}$ have revealed that the estimated available energy underestimates that measured (approx. 9\%). Knowing that the latent heat flux is estimated as the residual term of the energy balance equation in the model proposed for this specific study, any difference in the estimated available energy can be directly translated to the latent heat flux and produces an error in its estimation.

Finally, providing the sensible heat flux and the available energy estimates, the latent heat flux, $\mathrm{LE}_{\mathrm{mod}}$, is estimated by applying the first law of thermodynamics assuming the principle of conservation of energy. Figure 7 shows a comparison between the estimated $\mathrm{LE}_{\text {mod }}$ and the measured $\mathrm{LE}_{\mathrm{ec}}$ on a daily time scale. The RMSE value was approximately $31.42 \mathrm{Wm}^{-2}$, and the linear regression forced to the origin yielded a 0.94 slope value and a 0.75 correlation coefficient. In spite of the revealed discrepancies between $\mathrm{LE}_{\text {mod }}$ and $\mathrm{LE}_{\mathrm{ec}}$, the correspondence is deemed acceptable considering the difficulty in estimating latent heat flux over such a complex field. There are several explanations for this relatively large scatter between measured and estimated latent heat fluxes. First, the error associated with the estimated sensible heat flux can be translated in error in the estimation of $\mathrm{LE}_{\text {mod }}$. The difference is related to the effect of the contrast in the footprint scale, especially during the irrigation events. As reported previously, the footprint of the EC system covers a large area while the model used for local measurements, such as surface temperature, is derived from the radiometer. In order to illustrate the effect of the contrast in the footprint scale, a comparison is made during homogeneous (dry conditions and days following rain events) and heterogeneous conditions (during irrigation). Statistical results are presented in Table 2. It can be seen that the scatter obtained in $\mathrm{H}$ dur-

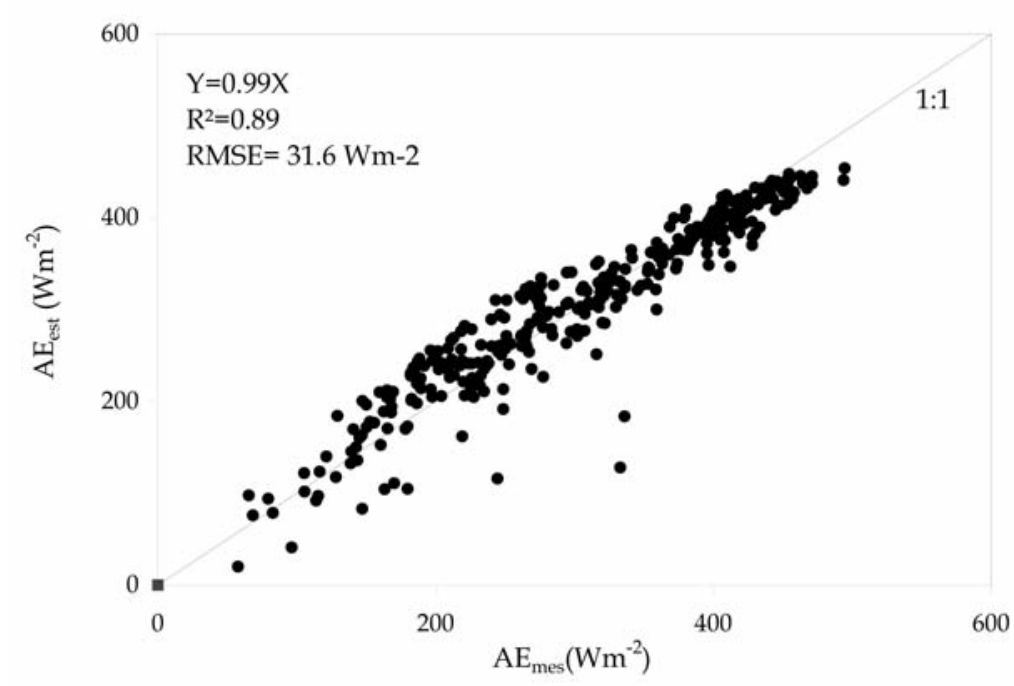

Figure 6. Comparison between daily estimated $\left(\mathrm{AE}_{\text {est }}\right)$ and measured $\left(\mathrm{AE}_{\mathrm{mes}}\right)$ available energy.

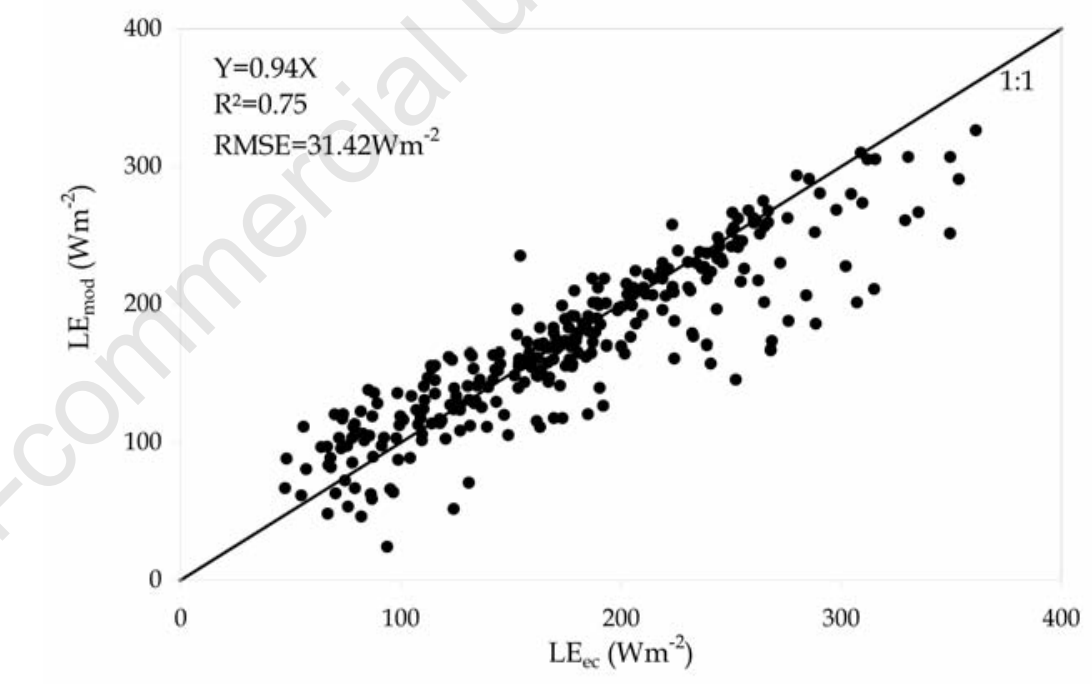

Figure 7. Comparison between daily modeled $\left(\mathrm{LE}_{\mathrm{mod}}\right)$ and measured $\left(\mathrm{LE}_{\mathrm{ec}}\right)$ latent heat flux.

Table 2. Statistical results of the comparison between: i) measured and modeled turbulent fluxes during homogeneous conditions (dry and days following rain events) and during heterogeneous (during irrigation) conditions; ii) estimated and measured available energy during cloudy and clear sky conditions.

\begin{tabular}{lcccc} 
& Slope & $\mathrm{R}^{2}$ & RVSE (Wm-2) \\
Homogeneous conditions & $\mathrm{H}$ & 1.03 & 0.91 & 22 \\
(dry conditions and days following rain events) & $\mathrm{LE}$ & 0.99 & 0.65 & 32 \\
Heterogeneous conditions & $\mathrm{H}$ & 0.93 & 0.68 & 31 \\
(during irrigation ) & $\mathrm{LE}$ & 0.87 & 0.53 & 42 \\
\hline Cloudy conditions & $\mathrm{AE}$ & 1.03 & 0.87 & 46 \\
Clear sky conditions & $\mathrm{AE}$ & 0.97 & 0.93 & 41 \\
\hline
\end{tabular}


ing heterogeneous conditions is clearly remarkable in LEmod. Second, since the LEmod is estimated as the residual term of the energy balance, any difference between measured and simulated available energy and the error associated to the energy balance closure is directly translated into error in the simulated $\mathrm{LE}_{\text {mod. }}$. Finally, part of the discrepancy can be related to the assumption of energy conservation which cannot be practically evaluated.

\section{Conclusions}

This study investigated the use of a soil-vegetation-atmosphere transfer model in conjunction with an energy balance model and Thermal Infra Red data (TIR) to estimate turbulent fluxes (sensible and latent heat) in difficult environmental conditions (tall vegetation, irrigation method which has an irregular pattern over space and time, and variable soil characteristics). An experiment was conducted over the irrigated olive grove of Agdal which is located in Marrakech (central Morocco) during the year 2003. Mass and energy fluxes, as well as micrometeorological parameters, were continuously collected during the year. A simple two-layer model was proposed to measure the sensible heat flux using the TIR data. In spite of the discrepancy observed, the daily sensible heat fluxes estimated from the model agreed reasonably well with those measured from the eddy covariance system $\left(\mathrm{R}^{2}=0.86, \mathrm{RMSE}=28\right.$ $\mathrm{Wm}^{-2}$ ). Therefore, it can be concluded that, in spite of its simplicity, the proposed model can be considered a good tool for monitoring the sensible heat fluxes over an extended period including all weather conditions (dry, moderate and wet). This study has also shown that when we combined these modeled fluxes of sensible heat with the available energy estimates using the TIR data, the latent heat fluxes can be reliably predicted over complex terrain in spite of the large scatter $\left(R^{2}=0.75\right.$ and RMSE $=31.42 \mathrm{Wm}^{-2}$ ) that is obtained when comparing the estimates against the Eddy covariance measurements.

The proposed approach to estimate turbulent fluxes used local measurements of surface temperature, albedo and solar radiation, and assumed that the source area of these measurements is comparable to the source area of the Eddy Covariance system which changes with wind direction during the day. This assumption can certainly lead to some errors in the comparison between modeled and measured turbulent fluxes, especially in wet conditions. Indeed, during the irrigation event, heterogeneity is observed at the source area scale of the eddy covariance. Finally, despite the limitations mentioned above, one can safely conclude that the proposed approach is reasonably adequate for routinely quantifying the values of turbulent fluxes over a complex field and thus monitoring the management of agricultural water resources.

\section{References}

1. Blad BL, Rosenberg NJ. Evaluation of resistance and mass transport evapotranspiration models requiring canopy temperature data. Agron J 1976;68:764-9.

2. Hatfield JL, Reginato RJ, Idso SB. Evaluation of canopy temperature-evapotranspiration models over various crops. Agr For Meteorol 1984;32:41-53.

3. Choudhury BJ, Reginato RJ, Idso SB. An analysis of infrared temperature observations over wheat and calculation of the latent heat flux. Agr For Meteorol 1986;37: 75-88.

4. Kustas WP, Norman JM, Schmugge TJ, Anderson MC. Mapping surface energy fluxes with radiometric temperature. In: DA Quattrochi, JC Luvall (eds.) Thermal remote sensing in land surface processes. Boca Raton, Florida: CRC Press, 2004, pp 205-53.

5. Norman JM, Anderson MC, Kustas WP. Are single-source, remote-sensing surfaceflux models too simple? In: G D'Urso, MA Osann Jochum, J Moreno (eds.) Proceedings of the international conference on earth observation for vegetation monitoring and water management. Am Inst Phys 2006;852:170-7.

6. Chehbouni A, Hoedjes JCB, Rodriquez JC, et al. Using remotely sensed data to estimate area-averaged daily surface over a semi-arid mixed agriculture land. Agr For Meteorol 2009;149:330-42.

7. Ezzahar J, Chehbouni A. The use of the scintillometry for validating the spatial and temporal aggregation schema over heterogeneous grid. Agr For Meteorol 2009;149:2098-109.

8. Norman JM, Kustas WP, Humes KS. A twosource approach for estimating soil and vegetation energy fluxes from observations of directional radiometric surface temperature. Agr For Meteorol 1995;77: 263-93.

9. Lhomme JP, Monteny B, Amadou M. Estimating sensible heat flux from radiometric temperature over sparse millet. Agr For Meteorol 1994;68:77-91.

10. Chehbouni A, Escadafal R, Duchemin B, et al. An integrated modelling and remote sensing approach for hydrological study in arid and semi-arid regions: the SUDMED Programme. Int J Remote Sens 2008;29: 5161-81.
11. Brutsaert W. Evaporation into the Atmosphere. Reidel, Dordrecht, 1982.

12. Paulson CA. The mathematical representation of wind speed and temperature profiles in the unstable atmospheric surface layer. J Appl Meteorol 1970;9:857-61.

13. Shuttleworth WJ, Gurney RJ. The theoretical relationship between foliage temperature and canopy resistance in sparse crops. Quart J Roy Meteorol Soc 1990; 116:497-519.

14. Lafleur PM, Rouse R. Application of an energy combination model for evaporation from sparse canopies. Agr For Meteorol 1990;49:135-53.

15. Choudhury BJ, Monteith JL. A four-layer model for the heat budget of homogeneous land surfaces. Quart J Roy Meteorol Soc 1988;114:373-98.

16. Ortega Farías S, Antonioletti R, Olioso A. Net radiation model evolution at an hourly time step for Mediterranean conditions. Agron 2000;20:157-64.

17. Jones HG, Archer N, Rotenberg E, Casa R. Radiation measurement for plant ecophys iology. J Exp Bot 2003;54:879-89.

18. Monteith JL, Unsworth MH. Principles of Environmental Physics. London: Edward Arnold, 1990.

19. Brutsaert W. On a derivable formula for long-wave radiation from clear skies. Water Resour Res 1975;11:742-4.

20. Norman JM, Kustas J, Prueger H, Diak GR. Surface flux estimation using radiometric temperature: A dual-temperature-difference method to minimize measurement errors. Water Resour Res 2000;36:2263-74.

21. Mecikalski JR, Diak GR, Anderson MC, Norman JM. Estimating fluxes on continental scales using remotely sensed data in an atmospheric-land exchange model. J Appl Meteorol 1999;38:1352-69.

22. Crawford TM, Stensrud DJ, Carlson TN, Capehart WJ. Using a soil hydrology model to obtain regionally averaged soil moisture values. J Hydrometeorol 2000;1:353-63.

23. Su Z. The surface energy balance system (SEBS) for estimation of turbulent heat fluxes. Hydrol Earth Syst Sci 2002;6:85-99.

24. Santanello JA, Friedl MA. Diurnal covariation in soil heat flux and net radiation. $\mathrm{J}$ Appl Meteorol 2003;42:851-62.

25. Wilczak J, Oncley S, Stage SA. Sonic anemometer tilt correction algorithms. Bound-Lay Meteorol 2001;99:127-50.

26. Schotanus P, Nieuwstadt F, De Bruin HAR. Temperature measurement with a sonic anemometer and its application to heat and moisture fluxes. Bound-Lay Meteorol 1983;26:81-93.

27. Moore CJ. Frequency response corrections for eddy-correlation systems. Bound-Lay Meteorol 1986;37:17-35.

28. Van Dijk A, Kohsiek W, De Bruin HAR. 
Oxygen sensitivity of krypton and lymanna hygrometers. J Atmos Oceanic Tech 2003;20:143-51.

29. Webb EK, Pearman GI, Leuning R. Correction of Flux Measurements for Density Effects Due to Heat and Water Vapor Transfer. Quart J Roy Meteorol Soc 1980;106:85-100.

30. Businger JA. 1986. Evaluation of the accuracy with which dry deposition can be measured with current micrometeorological techniques. J Clim Appl Meteorol 1986; 25:1100-24.

31. Goulden ML, Munger LW, Fan S-M, et al. Measurements of carbon sequestration by long-term eddy covariance: methods and a critical evaluation of accuracy. Global Change Biol 1996;2:169-82.

32. Moncrieff JB, Malhi Y, Leuning R. The propagation of errors in long-term measurements of land-atmosphere fluxes of carbon and water. Global Change Biol 1996;2:231-40.

33. Mahrt L. Flux sampling errors from aircraft and towers. J Atmos Oceanic Technol 1998; 15:416-29.

34. Twine TE, Kustas WP, Norman JM, et al. Correcting eddy-covariance flux estimates over a grassland. Agr For Meteorol 2000; 103:279-300.

35. Massman WJ, Lee X. Eddy covariance flux corrections and uncertainties in long term studies of carbon and energy. Agr For Meteorol 2002;113:121-44.

36. Morgenstern K, Black TA, Humphreys ER, et al. Sensitivity and uncertainty of the carbon balance of a Pacific Northwest Douglas-fir forest during an El Niño La Niña cycle. Agr For Meteorol 2004:123:20119.

37. Hollinger DY, Aber J, Dail B, et al. 2004. Spatial and temporal variability in forest- atmosphere C02 exchange. Glob Change Biol 2004;10:1689-706.

38. Testi L, Villalobos FJ, Orgaz F. Evapotranspiration of a young irrigated olive orchard in southern Spain. Agr For Meteorol 2004;121:1-18.

39. Baldocchi DD, Xu L, Kiang N. How plant functional-type, weather, seasonal drought, and soil physical properties alter water and energy fluxes of an oak-grass savanna and an annual grassland. Agr For Meteorol 2004;123:13-39.

40. Twine TE, Kustas WP, Norman JM, et al. Correcting eddy-covariance flux underestimates over a grassland. Agr For Meteorol 2000;103:279-300.

41. Ezzahar J, Chehbouni A, Hoedjes JCB, et al. The use of the Scintillation Technique for estimating and monitoring water consumption of olive orchards in a semi-arid region. Agr Water Manag 2007;89:173-84. 